\title{
Research on fabric characteristics and borehole instability mechanisms of fractured igneous rocks
}

\author{
Liu Xiangjun*, Zhu Honglin and Liang Lixi \\ State Key Laboratory of Oil and Gas Reservoir Geology and Exploitation, Southwest Petroleum University, Chengdu, \\ Sichuan 610500, China \\ (C) China University of Petroleum (Beijing) and Springer-Verlag Berlin Heidelberg 2013
}

\begin{abstract}
There are favorable exploration prospects in igneous rock reservoirs. However, problems of borehole instability occur frequently during drilling igneous formations, which is a serious impediment to oil and gas exploration and production. The lack of systematic understanding of the inherent instability mechanisms is an important problem. A series of experiments were conducted on several igneous rock samples taken from the sloughing formations in the Tuha area in an attempt to reveal the inherent mechanisms of wellbore instability when drilling in fractured igneous rocks. Research methods involved slurry chemistry, analysis of micro-geological features (Micro-CT imaging, SEM), and rock mechanics testing. The experimental results indicated that clay minerals were widely distributed in the intergranular space of the diagenetic minerals, crystal defects, and microcracks. Drilling fluid filtrate would invade the rock along the microcracks. The invasion amount gradually increased over time, which constantly intensified the hydration and swelling of clay minerals, leading to changes in the microscopic structure of igneous rocks. Primary and secondary microcracks can propagate and merge into single cracks and thus reducing rock cohesion and the binding force along cleavage planes. Based on this result the authors propose that a key towards solving wellbore instability in igneous formations is that specific micro-geological characteristics of the igneous rocks should be taken into consideration in the design of antisloughing drilling muds.
\end{abstract}

Key words: Igneous rocks, microcracks, clay minerals, hydration, instability

\section{Introduction}

Borehole instability caused by clay mineral hydration during drilling is a major problem in the oil industry. This phenomenon usually occurs in the clay-rich mud shale; however, with expansion of exploration, it is also found in the drilling of igneous formations (Mitsuhata et al, 1999; Sahabudin and Darren, 2000). In recent years, borehole collapse, hole enlargement, lost circulation, pipe sticking and other complex problems often emerge in most of oil and gas basins when drilling into igneous rocks (basalt, tuff-based), resulting in the expansion of the drilling cycle and increase in drilling cost. To reduce wellbore instability problems in igneous rock formations, several researchers have investigated the factors influencing borehole instability. Researchers focusing on metasomatic alteration petrology pointed out that the neutral or basic igneous rocks, especially pyroclastic rocks under hydrothermal conditions (contact with the formation fluid under high temperature conditions) would be vulnerable to argillization. Plagioclase is often altered to kaolinite and smectite minerals. Numerous studies show that clay minerals in igneous rock formations tending

*Corresponding author. email: liuxiangjunswpi@163.com Received August 31, 2012 to suffer from borehole instability consist mainly of smectite, whose physical and chemical properties present strong dispersibility or expansibility (Bhuyan and Passey, 1994; Stjern et al, 2003; Thomson, 2003; Rohrman, 2007). When contacted with incompatible drilling fluid filtrate, these clay minerals would be hydrated (in the forms of dispersion or expansion), thus leading to wellbore instability. In the Jidong Oilfield, the basalt and tuff formations in the Guantao Group where borehole instability occurs contain a large number of clay minerals, up to $36 \%-78 \%$, with a relative content of smectite of $90 \%-97 \%$. The high content and wide distribution of opaline silica which also expands easily may also be one of the reasons for borehole instability (Yuan et al, 2007). Tuff is easily to disperse, with a core recovery rate of less than $10 \%$, while basalt and altered basalt have relatively low dispersibility, but still expand easily with an expansion ratio up to $38 \%-43 \%$ (Zhang et al, 2010).

In addition, the particular petrological structure of igneous rocks is also a potential factor of borehole instability (Sato et al, 1999; Kawamoto and Sato, 2000; Jerram et al, 2009; Karakul and Ulusay, 2009; Wang et al, 2010). Weak planes and non-homogeneous structure greatly weakens the strength of formation rock. Moreover, the micro-structures of igneous rocks also have an impact on the deformation mode (Crosta et al, 2010; Hossain and Seshagiri, 2008; Lutz et al, 2010), 
so that the traditional Hoek-Brown instability criterion is no longer applicable (Masoumi and Douglas, 2012). The hardness of amygdaloid differs substantially from that of the basalt matrix drilled in amygdaloidal basalt in the Tahe Oilfield (the amygdaloid are composed of calcite, opaline silica, and chlorite). The released stress, surge pressure, drilling tool collision, and other mechanical factors during drilling make it easy to produce stress concentration at the amygdale, which results in sloughing of surrounding rock and lost circulation in basalt with abundant pores ( $\mathrm{Li}$ et al, 2011). Several researchers (Assefa and Sothcott, 1997; Tziallas et al, 2009; Cavinato et al, 2005; Bauer et al, 1981) focused more on investigating the factors affecting the geo-mechanical properties of rocks and the relationship with acoustic parameters, but they did not pay attention to understanding the mechanisms of borehole instability in igneous formations. The understanding obtained from the studies on drilling fluids used in igneous formations (Tan et al, 1998; Aburto and Clyde, 2009; Chen et al, 2003) was that the original collapse pressure of the igneous rock was high and wellbore stabilization was achieved by continuously adjusting the drilling fluid density. But so far, when wellbore instability occurs in newly drilled igneous rocks (such as Yubei), it is still necessary to take a lot of time and effort to come up with countermeasures. The fundamental reason is the lack of a clear and systematic understanding of the mechanisms of wellbore instability in igneous rock formations.

In view of the above problems, which are related to physical and mechanical properties of igneous rocks under specific geological and engineering conditions, a series of experiments were conducted on several igneous rock samples taken from the sloughing formations in the Tuha area, to attempt to reveal the inherent instability mechanisms of these fractured igneous rocks.

\section{Microstructure and clay mineral analysis of igneous rocks}

The mechanical properties of rocks are affected by mineral composition, rock texture, clay content and clay type. Therefore, analysis of mineral component, rock texture, and clay type and content of igneous rocks may greatly contribute to understanding the borehole instability mechanisms.

\subsection{Whole-rock mineral analysis by X-ray diffraction (XRD)}

$\mathrm{X}$-ray diffraction analysis is a fast, reliable and convenient method for determining clay mineral type and content. Several rock samples taken from the sloughing formations in the study area were ground to fine powder and then XRD was applied to determine the total clay mineral content in the powder. Compared with the intercrystalline distance and intensity of diffracted ray for different types of clay minerals, the types and relative contents of clay minerals were identified. The results of XRD analysis showed that both types of igneous rock samples had high clay contents (see Figs. 1 and 2). The average clay content of the tuff samples was $18 \%$ and that of the basalt samples was $23 \%$.

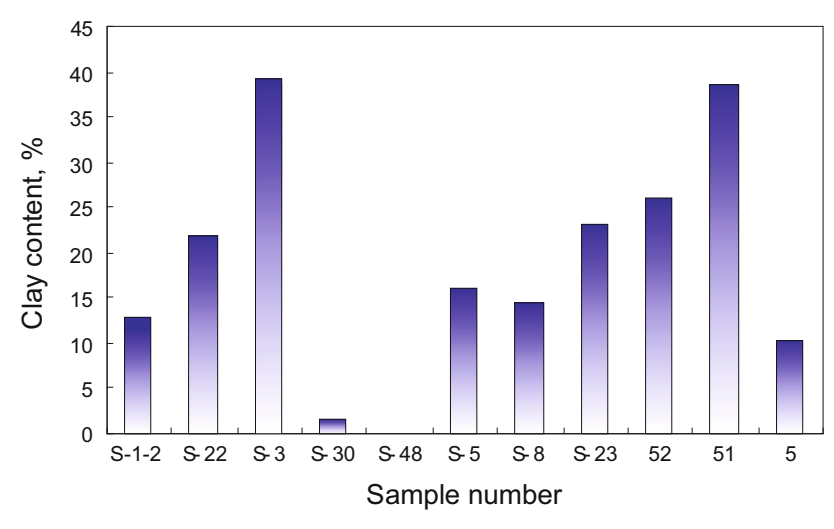

Fig. 1 Whole-rock mineral analysis of clay content in tuff specimens

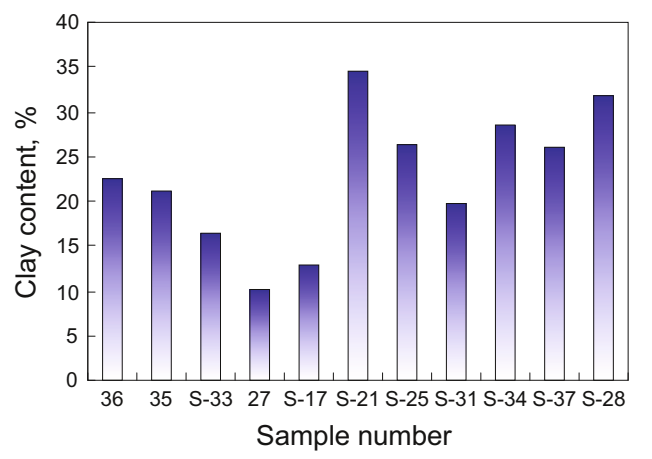

Fig. 2 Whole-rock mineral analysis of clay content in basalt specimens

Table 1 lists the clay mineral composition of some test samples. It can be seen from Table 1 that in all test samples, the dominant clay mineral is smectite; in the four main clay minerals (kaolinite, chlorite, illite, and smectite), the relative percentages of smectite is generally more than $50 \%$, except samples S-32 and S-28, even exceeding 95\%. The relative contents of smectite in samples S-32 and S-28 are 19\% and $32 \%$, respectively.

Table 1 Clay mineral content and composition

\begin{tabular}{cccccc}
\hline \multirow{2}{*}{ Sample } & $\begin{array}{c}\text { Total clay mineral } \\
\text { content, } \%\end{array}$ & \multicolumn{4}{c}{ Relative content, \% } \\
\cline { 3 - 5 } S-3 & 39 & 0.1 & 0.2 & 3.8 & 96 \\
S-47 & 13 & 0.3 & 0.2 & 0.8 & 99 \\
S-9 & 15 & 0.0 & 0.1 & 0.3 & 99 \\
S-22 & 22 & 0.1 & 0.2 & 0.6 & 99 \\
S-26 & 26 & 21.2 & 14.2 & 0.0 & 65 \\
S-32 & 16 & 31.2 & 15.6 & 34.7 & 19 \\
S-28 & 32 & 50.3 & 16.8 & 0.5 & 32 \\
S-23 & 23 & 0.3 & 0.2 & 0.8 & 99 \\
52 & 26 & 0.1 & 0.2 & 0.4 & 99 \\
36 & 23 & 0.0 & 22.7 & 6.1 & 71 \\
53 & 10 & 0.3 & 0.2 & 46.6 & 53 \\
5 & 39 & 0.6 & 0.7 & 2.0 & 97 \\
\hline
\end{tabular}


Scanning electron microscopy (SEM) is an extremely useful technique commonly used to observe the microscopic structure of clay minerals and their occurrence modes. Fig. 3 shows the morphological characteristics of clay minerals in a basalt sample. It can be seen from the SEM image (Fig. 3(a)) that clay minerals in the basalt samples were well developed. Smectite was identified in the scanning electron micrographs at a magnification of up to 2,000 times (Fig. 3(b)).

Fig. 4 shows the morphological characteristics of clay minerals in a tuff sample. The SEM results showed that a large number of clay minerals were observed in the intergranular space, crystal defects and the micro-cracks of the diagenetic minerals, in both types of specimen. The main mineral occurred as a small flaky texture, which was identified as smectite.

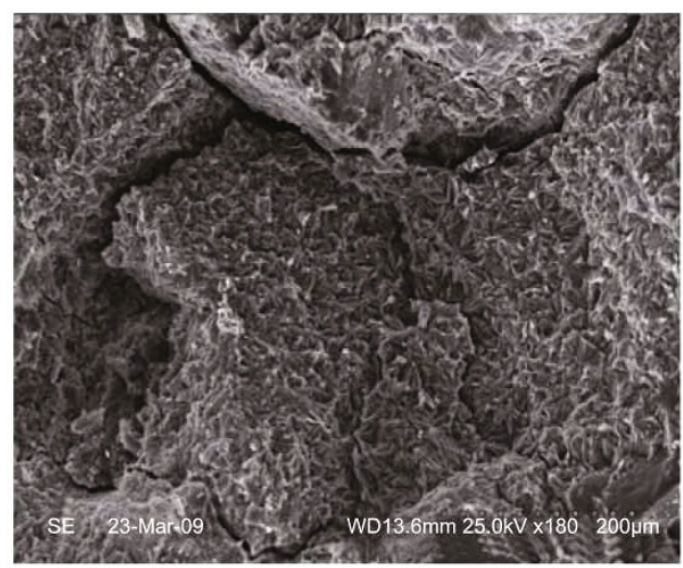

(a)

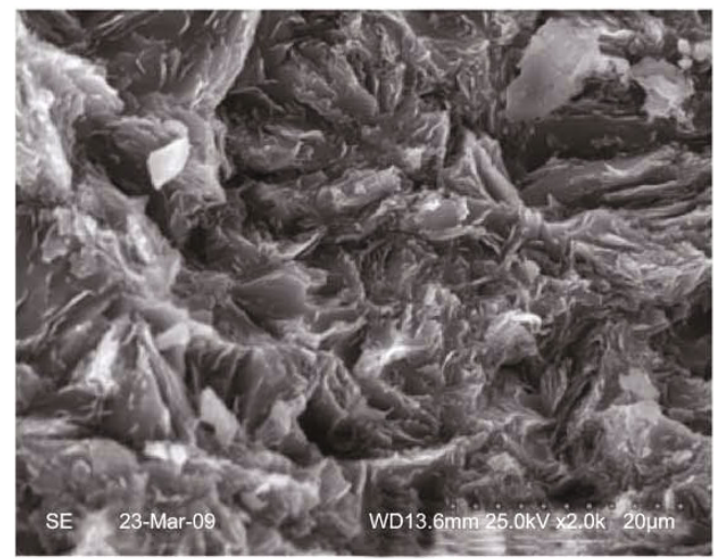

(b)

Fig. 3 Microscopic morphology of clay minerals in a basalt sample (S-28)

\subsection{Weak structural plane and microscopic pore structure description}

The development of cracks, cleavage, and weak structural planes directly determine the rock mechanical properties. This also affects the permeability in vicinity of the wellbore. Analysis of drill core samples from the study area (Fig. 5)

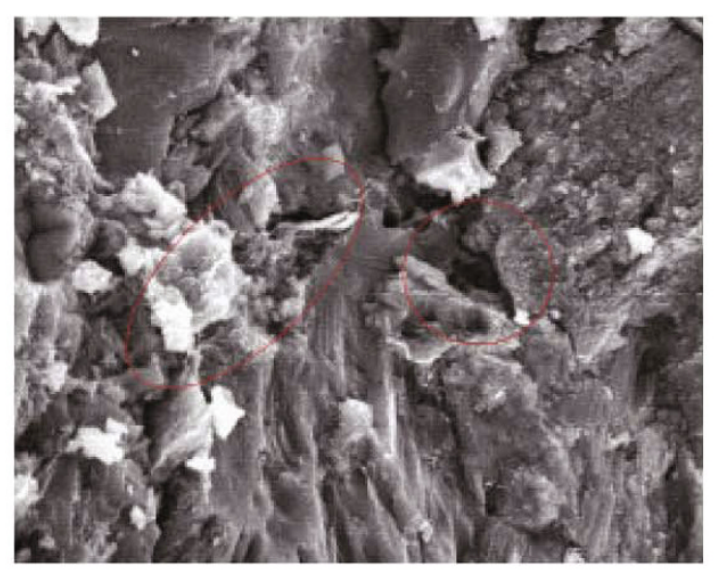

(a) Clay minerals in micropores

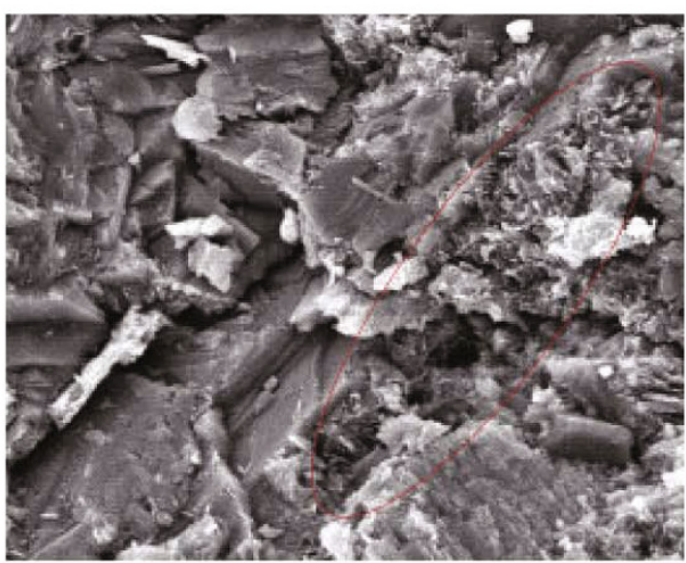

(b) Clay minerals in microcracks

Fig. 4 Microscopic morphology of clay minerals in micropores and microcrack present in a tuff sample (S-32)

indicated that the underground igneous rocks exhibited a strong heterogeneity, and weak planes were well developed, most of which were filled with other minerals, showing banded mineral filling characteristics (Fig. 5(c), 5(d)). However, there were also developed a small number of unfilled cracks (Fig. 5(a)).

Fig. 6 shows the microscopic structures of basalt and tuff samples obtained with the scanning electron microscope. A small number of pores were observed in both basalt and tuff samples. They were mainly intergranular micropores, which were connected by microcracks and cleavage planes widely distributed in the samples. The existence of abundant micropores, microcracks and cleavage planes greatly reduced the mechanical properties of igneous rocks, so the rock mass may be easily damaged by external force along the microcracks and cleavage planes, finally resulting in wellbore instability. On the other hand, these micropores, microcracks and cleavage planes also provided channels or passages for the water phase of the drilling fluid penetrating into the formation and interacting with clay minerals (especially the smectite), increasing the possibility of the invasion of drilling fluid filtrates deep into the formation. During drilling in this area, when drilling fluid filtrates penetrate into the formation 


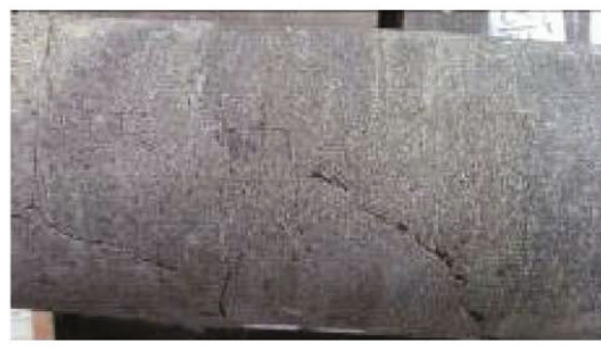

(a) Fissure

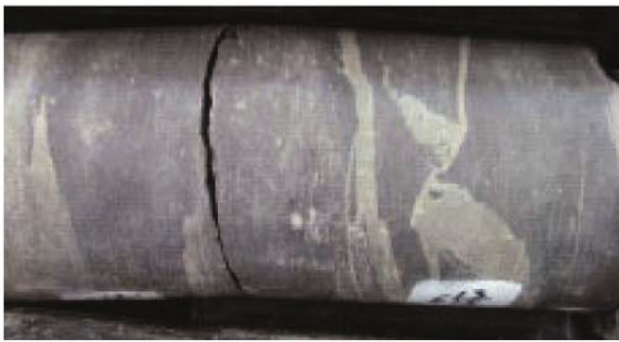

(c) Filled fissure

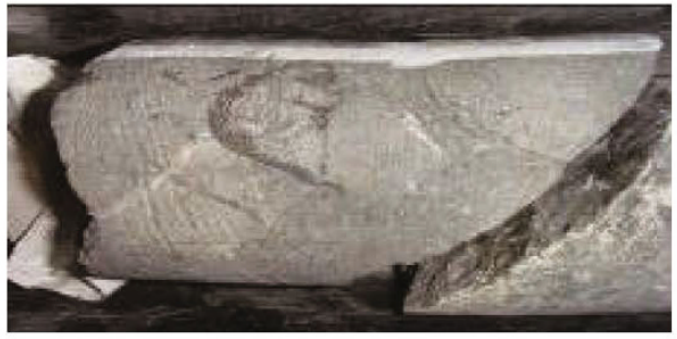

(b) Weak plane

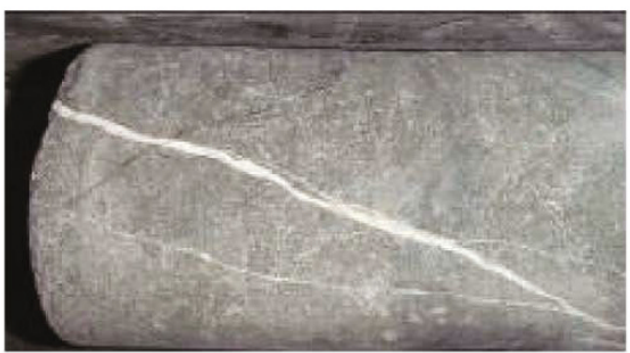

(d) Filled fissure and weak plane

Fig. 5 Weak planes in full-size drilling cores

along the microcracks or cleavage planes, the filtrates often exacerbate the hydration, expansion and dispersion of clay minerals, thereby reducing the bonding strength of the rock and the binding force between cleavage planes, then causing

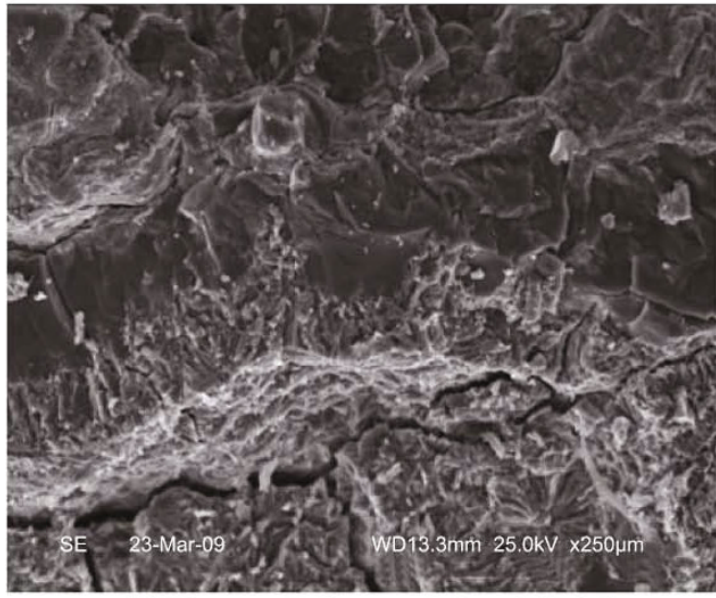

(a) Microscopic fissures in basalt (S-21)

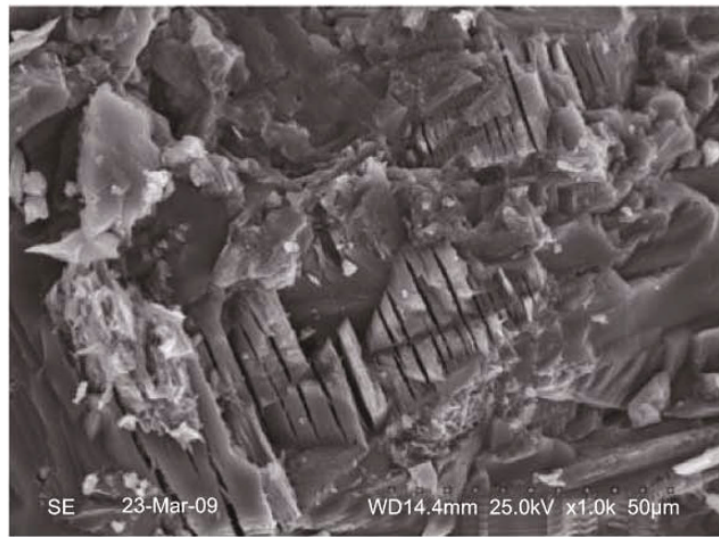

(c) Microscopic cleavage plane in tuff (S-9, unloading) it split along the cleavage planes or microcracks, finally resulting in wellbore instability. When the filtrate loss of the drilling fluid gets higher, it can easily lead to borehole sloughing and sticking.

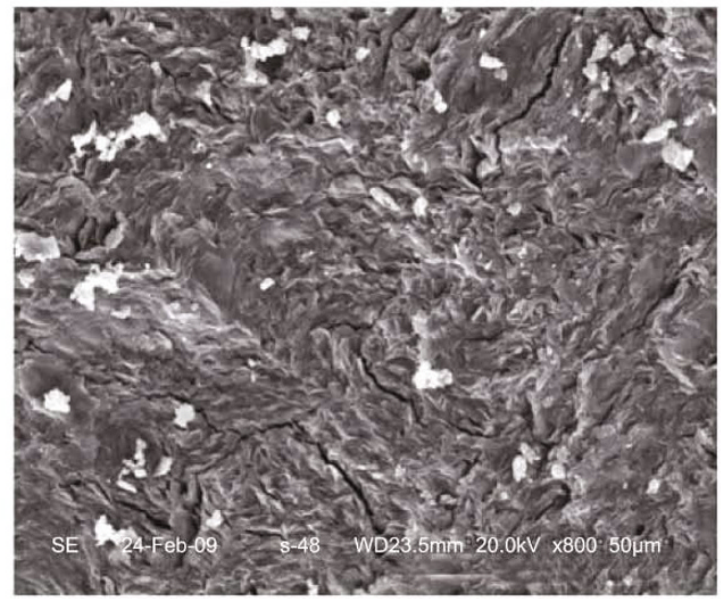

(b) Microscopic fissures in basalt (S-48)

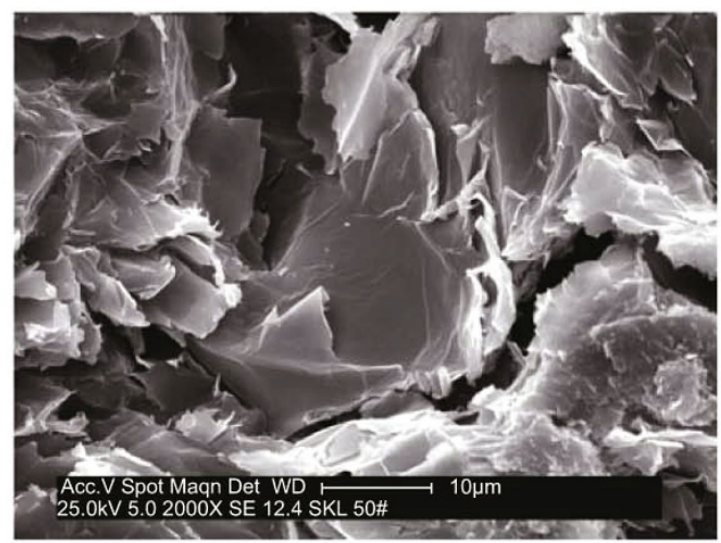

(d) Microscopic fissures in tuff (S-25)

Fig. 6 SEM images of basalt and tuff samples 


\section{Mechanical properties of rock samples after soaking in the drilling fluid}

To further investigate the instability mechanisms of the fractured igneous rocks, the mechanical properties of rock samples were measured after soakng in the drilling fluid (Table 2). Triaxial compression tests were conducted to analyze the dynamic characteristics of rock samples after soaking in the drilling fluid for different times. To guarantee the comparability of the experimental results, from the same lithologic type of core samples, we selected integrated samples with similar initial density and initial acoustic travel time as experimental core samples (Table 3 ).

Table 2 Drilling fluid formulation

\begin{tabular}{cc||cc}
\hline Component & Content, \% & Component & Content, \% \\
\cline { 2 - 3 } KPAM & 0.3 & NaCOOH & 5 \\
HV-PAC & 0.5 & WD801 & 1 \\
XC & 0.3 & BST-II & 0.5 \\
NaHPAN & 1.5 & HV-CMC & 0.5 \\
LYDF & 3.0 & SPNH & 2 \\
\hline
\end{tabular}

Table 3 Basic parameters of core samples

\begin{tabular}{ccccc}
\hline $\begin{array}{c}\text { Sample } \\
\text { number }\end{array}$ & $\begin{array}{c}\text { Density } \\
\mathrm{g} / \mathrm{cm}^{3}\end{array}$ & $\begin{array}{c}\text { Acoustic time } \\
\mu \mathrm{s} / \mathrm{m}\end{array}$ & $\begin{array}{c}\text { Porosity } \\
\%\end{array}$ & $\begin{array}{c}\text { Permeability } \\
\times 10^{-2} \mathrm{mD}\end{array}$ \\
\hline 2 & 2.52 & 225.4 & 3.6 & 1.5 \\
10 & 2.57 & 232.3 & 2.9 & 5.1 \\
11 & 2.58 & 233.1 & 3.8 & 6.2 \\
12 & 2.58 & 252.0 & 4.7 & 6.8 \\
45 & 2.53 & 242.5 & 4.2 & 2.2 \\
46 & 2.46 & 229.5 & 3.7 & 2.6 \\
47 & 2.53 & 237.7 & 4.1 & 1.7 \\
53 & 2.54 & 238.5 & 3.9 & 1.6 \\
\hline
\end{tabular}

The core samples were soaked in the drilling fluid for 24,48 , and $72 \mathrm{~h}$, respectively, at atmospheric temperature and pressure. During soaking, the acoustic travel time, and mass, and densities of core samples measured at certain time intervals. Finally, triaxial compression tests were conducted under the simulated formation confining pressure.

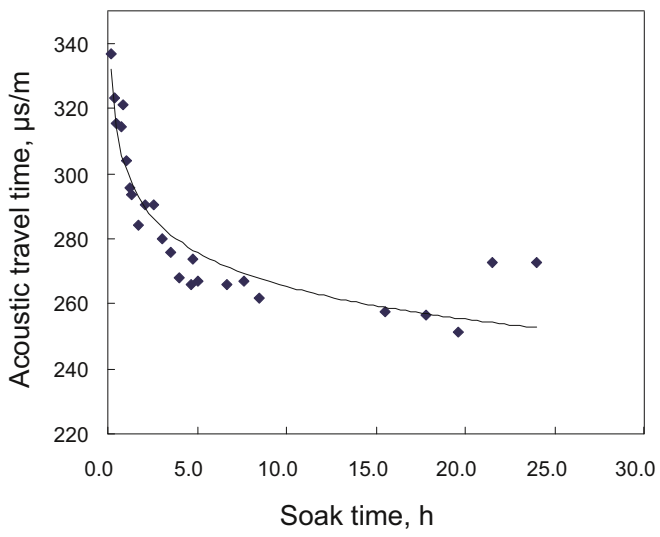

(a)
It can be seen from Fig. 7(b) that both the mass and density of the core samples increased with soak time. This indicated that the amount of drilling fluid filtrate invading the core samples gradually increased over time and the core sample was not yet full affected by the drilling fluid within 72 $\mathrm{h}$.

Previous research indicated that the acoustic velocity increased with an increase in fluid saturation (Pujol and Smthson, 1991; Wang and Dai, 2006; Zhu et al, 2011). In these tests, the drilling fluid filtrate invaded the core sample as it was soaked, so the fluid saturation increased in the sample and the effective pore space with gas decreased due to swelling of clay minerals which are sensitive to water. This resulted in a reduction in acoustic travel time (i.e. increase in wave velocity) of the core samples (Fig. 7(a)). Thus even without external pressure difference, the drilling fluid filtrate may invade the core sample and react with clay minerals under capillary pressure when the core sample was soaked in the drilling fluid. This is an important factor for the reduction of rock strength. Triaxial compression test results showed that the compressive strength of igneous rock sample was significantly lower after soaking than its initial value, and the overall elasticity modulus also decreased (Fig. 8).

The experimental results showed that drilling fluid invasion significantly reduced the mechanical strength of the igneous rocks. However, the reduction of the rock mechanical properties is only the representation in macro physics, which cannot reveal the intrinsic yield failure of rocks. This cannot describe the relationship between the internal structure of the rock and its mechanical properties (Sulukcu and Ulusay, 2001). The question is: how does the interaction between the drilling fluid and the microcracks and the clay minerals change the rock structure, affect the propagation of the internal cracks, and then reduce the stability of the igneous rock? In our laboratory, a micro-CT scanner was used to image the igneous core samples before and after soaking in the drilling fluid to record visually the subtle evolution of microcracks in core samples, thus revealing the intrinsic failure mechanism.

The microcracks were found to present an increasing trend with soak time (Fig. 9). With the continuous invasion of the drilling fluid filtrate, propagating microcracks tended to bifurcate in the core samples until full communication

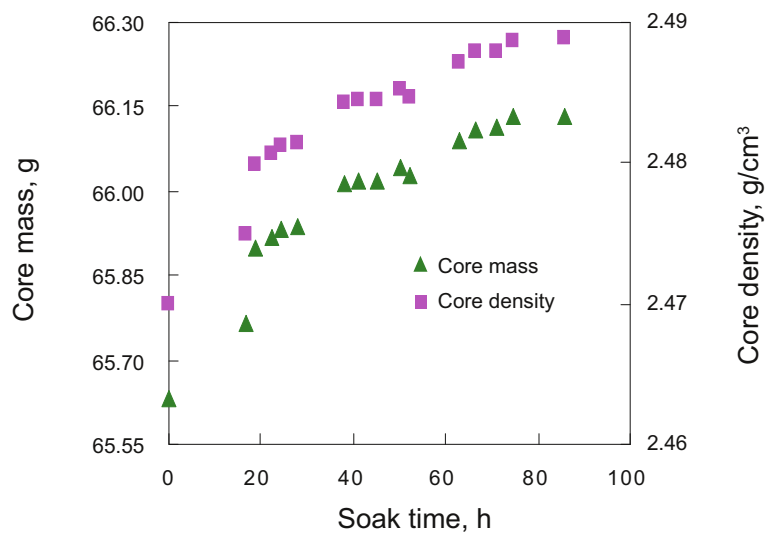

(b)

Fig. 7 Petrophysical properties of core sample S-12\# after different times of soaking 


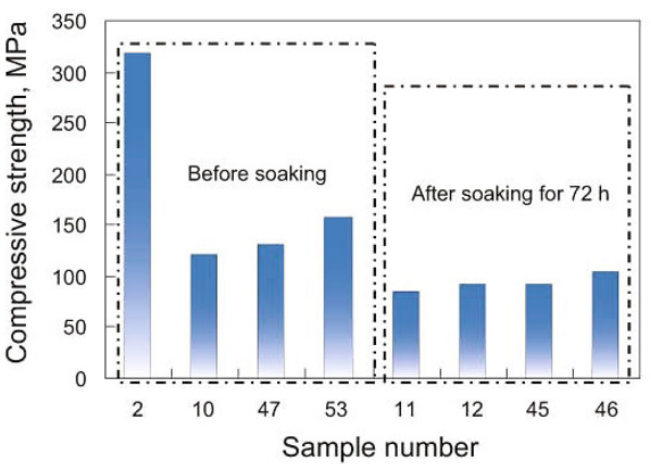

(a)

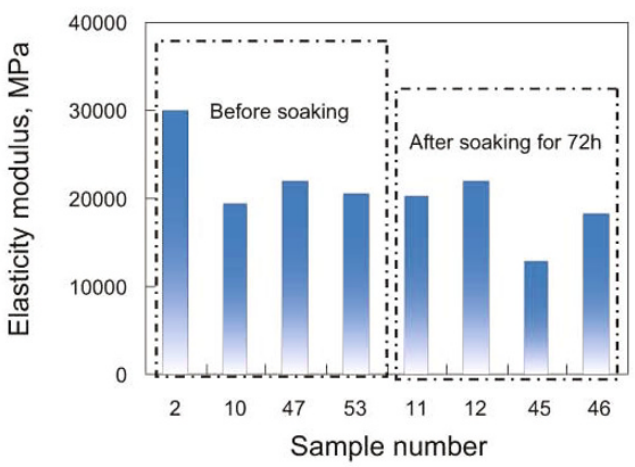

(b)

Fig. 8 Effect of drilling fluid invasion on mechanical parameters

occurred. The depth of crack propagation was related to the degree of development of the initial cracks. Filtrate invasion and the corrosion and erosion of clay minerals in weak planes would decrease the friction strength of the surface of weak planes and lead to the microcracks being interconnected with the main crack, resulting in macroscopic damage. This resulted in a decrease in rock strength at the borehole wall with weak planes and then borehole sloughing during drilling. For the basalt block with higher hardness, even more complicated conditions such as sticking would occur.
Fig. 10 shows the photos of specimens S-9 and S-7 which were soaked in the drilling fluid for $48 \mathrm{~h}$. Cracks and disintegration of rock were observed on the end portion of the specimen under atmospheric pressure. Combined with CT scan analysis, we drew the conclusion that continuous propagation and evolution of internal microcracks would communicate themselves with the cracks on the core surface, which reduced the binding force between layers, then caused the end portion to flake off the block. Therefore, based on the micro-geological characteristics analysis in this paper, we

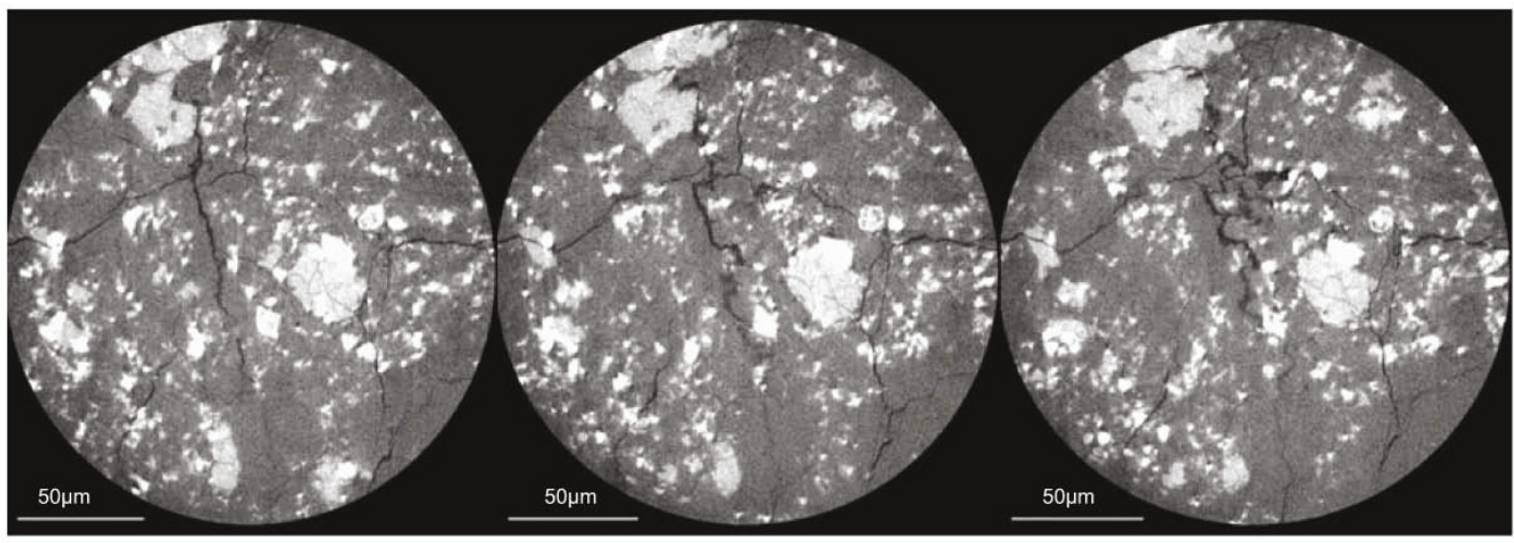

(a) Before soaking

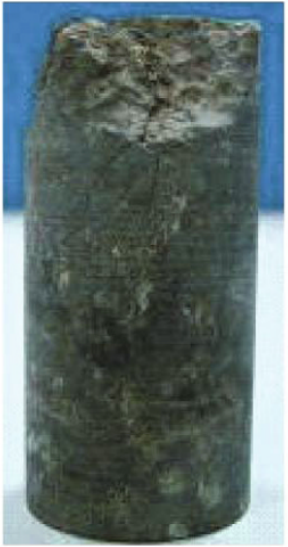

(a) Sample S-9

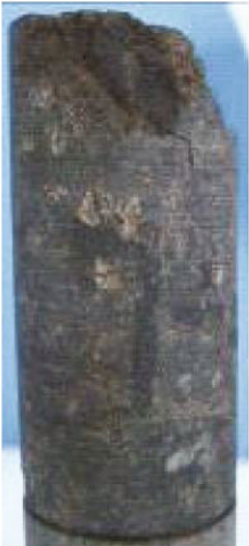

(a) Sample S-7 (b) After soaking for $48 \mathrm{~h}$

Fig. 9 CT-scan images (c) After soaking for $72 \mathrm{~h}$

Fig. 10 The end of core flaked off after immersion

summarized a failure mechanism of borehole instability in fractured igneous rocks formations. The drilling fluid filtrate can penetrate along the cracks and microcracks and react with some clay minerals (swelling and hydration), which causes a decrease in cohesion of mineral particles. Therefore, primary or secondary microcracks may continuously propagate and merge into single cracks until partial or total collapse occur in the core samples.

\section{Conclusions}

1) XRD and SEM analyses indicate that clay minerals are common in the intergranular space of the diagenetic minerals, crystal defects, and microcracks. The dominant clay mineral is smectite.

2) Triaxial compression test results show that the 
compressive strength of an igneous rock sample is significantly lower after soaking in drilling fluid filtrate than its initial value, and the overall elasticity modulus also decreases.

3) Micro-CT imaging indicates that primary and secondary microcracks may propagate and merge into single cracks due to invasion of the drilling fluid filtrate, leading to partial collapse of the rock.

4) The inherent instability mechanism of fractured igneous rocks is revealed. The presence of weak planes, microcracks and cleavage planes in the igneous rock exacerbates the hydration and swelling of clay minerals, and thereby changes the mechanical properties of rock in the vicinity of the borehole. This eventually causes borehole instability.

\section{Acknowledgements}

The authors are grateful for financial support from the National Natural Science Foundation of China (Grant No. U1262209).

\section{References}

Aburto $\mathrm{M}$ and Clyder R. The evolution of rotary steerable practices to drill faster, safer and cheaper deepwater salt sections in the Gulf of Mexico. SPE/IADC Drilling Conference and Exhibition, 17-19 March 2009, Amsterdam, Netherlands (SPE118870-MS)

Assefa S and Sothcott J. Acoustic and petrophysical properties of seafloor bedrocks. SPE Formation Evaluation. 1997. 12(3): 158-163 (SPE 37164)

Bauer S J, Friedman M and Handin J. Effects of water-saturation on strength and ductility of three igneous rocks at effective pressures to $50 \mathrm{MPa}$ and temperatures to partial melting. American Rock Mechanics Association, 29 June - 2 July, 1981, Cambridge

Bhuyan K and Passey Q R. Clay estimation from GR and neutrondensity porosity logs. The 35th Annual Logging Symposium Transactions. Society of Professional Well Log Analysts, 1994

Cavinato G P, Cravero M, Iabichino G, et al. Geostructural and geomechanical characterization of rock exposures for an endangered alpine road. American Rock Mechanics Association, 25-29 June 2005, Anchorage, AK

Chen X, Tan C P and Detournay C. A study on wellbore stability in fractured rock masses with impact of mud infiltration. Journal of Petroleum Science and Engineering. 2003. 38(1): 145-155

Crosta G, Agliardi F, Fusi N G, et al. Rock fabric controls on the failure mode of strongly deformed gneisses. International Society for Rock Mechanics, 15-18 June 2010, Lausanne, Switzerland

Hossain N K and Seshagiri R. Role of the texture characteristics on the strength properties of crystalline rocks. ISRM International Symposium-5th Asian Rock Mechanics Symposium, 24-26 November 2008, Tehran, Iran

Jerram D A, Single R T, Hobbs R W, et al. Understanding the offshore flood basalt sequence using onshore volcanic facies analogues: An example from the Faroe-Shetland basin. Geological Magazine. 2009. 146: $353-367$

Kawamoto T and Sato K. Geological modelling of a heterogeneous volcanic reservoir by the petrological method. SPE Asia Pacific Conference on Integrated Modelling for Asset Management, 25-26 April 2000, Yokohama, Japan (SPE 59407)

Karakul H and Ulusay R. Evaluation of strength anisotropy and empirical models for estimating strength of rock materials with inclined weakness planes using block punch index test. ISRM International Symposium on Rock Mechanics, 19-22 May 2009,
Hong Kong, China

Li J S, Du S, Mao H T, et al. Research and application of drilling fluid technology in igneous rock formation of deep exploration wells in Tuha. Petroleum Geology and Engineering. 2011. 25(Suppl.): 49-52 (in Chinese)

Lutz S J, Cline E J and Martin J W. Rock mechanical testing for the desert peak enhanced geothermal system (EGS) project, Nevada. American Rock Mechanics Association, 27-30 June 2010, Salt Lake City, Utah

Masoumi H and Douglas K J. Experimental study of size effects of rock on UCS and point load tests. American Rock Mechanics Association, 24-27 June 2012, Chicago, Illinois

Mitsuhata Y, Matsuo K and Minegishi M. Magnetotelluric survey for exploration of a volcanic rock reservoir in the Yurihara oil and gas field, Japan. Geophysical Prospecting. 1999. 47(2): 195-218

Pujol J and Smthson S. Seismic wave attenuation in volcanic rocks from VSP experiments. Geophysics. 1991. 56(9): 1441-1455

Rohrman M. Prospectivity of volcanic basins: Trap delineation and acreage de-risking. AAPG Bulletin. 2007. 91(6): 915-939

Sahabudin S and Darren E. Reducing well costs by optimizing drilling including hard/abrasive igneous rock section offshore Vietnam. IADC/SPE Asia Pacific Drilling Technology, 11-13 September 2000, Kuala Lumpur, Malaysia (SPE 62777)

Sato K, Wright C A and Ichikawa M. Post-frac analyses indicating multiple fractures created in a volcanic formation. SPE India Oil and Gas Conference and Exhibition, 17-19 February 1998, New Delhi, India (SPE 39513)

Stjern G, Agle A and Horsrud P. Local rock mechanical knowledge improves drilling performance in fractured formations at the Heidrun field. Journal of Petroleum Science and Engineering. 2003. 38(1): 8396

Sulukcu S and Ulusay R. Evaluation of the block punch index test with particular reference to the size effect, failure mechanism and its effectiveness in predicting rock strength. International Journal of Rock Mechanics \& Mining Sciences. 2001. 38: 1091-1111

Tan C P. Integrated rock mechanics and drilling fluid design approach to manage shale. SPE/ISRM Rock Mechanics in Petroleum Engineering, 8-10 July 1998, Trondheim, Norway (SPE 47259)

Thomson K. Extrusive and intrusive magmatism in the North Rockall Trough. Petroleum Geology. 2003. 2(10): 6-9

Tziallas G P, Tsiambaos G and Saroglou H. Rock strength and deformability measurements with indirect methods. ISRM International Symposium on Rock Mechanics, 19-22 May 2009, Hong Kong, China

Wang J G, Liu H Q and Zhao X. Studies on fracture-identification of the volcanic-rock reservoir by well logging. International Oil and Gas Conference and Exhibition, 8-10 June 2010, Beijing, China (SPE 130965)

Wang L and Dai H. Estimating anisotropic parameters from PS converted-wave data. Journal of Seismic Exploration. 2006. 1(10): 1-3

Yuan S Y, Ran Q, Xu Z S, et al. Strategy of high-efficiency development for volcanic gas reservoirs. Acta Petrolei Sinica. 2007. 28(1): 73-77 (in Chinese)

Zhang L W, Li J H, Yu H Y, et al. Characteristics and distribution prediction of lithofacies of Carboniferous igneous rocks in Dixi area, East Junggar. Acta Petrologica Sinica. 2010. 26(1): 263-273 (in Chinese)

Zhu H L, Liu X J and Liu H. Experimental research on effects of gas saturation on acoustic wave velocity of carbonate rock. Chinese Journal of Rock Mechanics and Engineering. 2011. 30(Supp1.): 2784-2789 (in Chinese) 